\title{
Surgical Outcomes After Pancreaticoduodenectomy in Elderly Patients
}

\author{
Kazuhiro Suzumura*, Kenjiro Iida, Hideaki Iwama, Yusuke Kawabata \\ Department of Surgery, Hyogo College of Medicine, Hyogo, Japan \\ Email address: \\ ssuzumu@hyo-med.ac.jp (K. Suzumura) \\ ${ }^{*}$ Corresponding author \\ To cite this article: \\ Kazuhiro Suzumura, Kenjiro Iida, Hideaki Iwama, Yusuke Kawabata. Surgical Outcomes After Pancreaticoduodenectomy in Elderly Patients. \\ Journal of Surgery. Vol. 7, No. 4, 2019, pp. 114-118. doi: 10.11648/j.js.20190704.16
}

Received: June 7, 2019; Accepted: July 15, 2019; Published: August 5, 2019

\begin{abstract}
Background: Pancreaticoduodenectomy (PD) is an aggressive surgery with considerable operative risks. Objective: The purpose of this study was to evaluate the safety of $P D$ in patients of $\geq 75$ years of age and to show the influence of advanced age on the mortality and morbidity associated with PD. Methods: Between July 2009 and December 2013, 131 patients underwent PD at Hyogo College of Medicine. We analyzed the perioperative data and outcomes after PD in patients of $\geq 75$ years of age (elderly group) in comparison to those of patients of $<75$ years of age (younger group). Results: There were no differences between the elderly group $(n=28)$ and younger group $(n=103)$ in terms of gender, body mass index (BMI), biochemistry test results, operative time or intraoperative blood loss. There were significant differences in the incidence of preoperative complications in the elderly and younger groups. There were no differences in the rates of mortality $(0 \%$ vs. $1 \% ; p=0.601)$ or morbidity ( $64 \%$ vs. $49 \%$; $p=0.139$ ). Morbidities included pancreatic fistula, delayed gastric emptying, intra-abdominal bleeding, intra-abdominal abscess, ascites and pneumonia. Conclusion: The preoperative complication rate in the elderly group was significantly higher than that in the younger group. However, PD can be performed safely in elderly patients and advanced age alone should not be a contraindication to PD.
\end{abstract}

Keywords: Pancreaticoduodenectomy, Elderly Patients, Outcome

\section{Introduction}

The elderly population has been increasing in many developed countries. The aging population worldwide has resulted in more elderly patients undergoing major surgery, such as pancreaticoduodenectomy (PD). PD has long been associated with high rates of mortality and morbidity [1-5]. With advances in surgical management for PD, the mortality rate has been reported to have decreased to less than 5\% [6-7]. However, the morbidity rate of PD has still been reported to be 30-60\%, with morbidities including pancreatic fistula, delayed gastric emptying, intra-abdominal bleeding and intra-abdominal abscess [8-9]. Thus, surgeons should carefully consider whether PD will be beneficial for their elderly patients. Some studies have reported the increased surgical risk of elderly patients who undergo PD [10-12], while others have reported the safety and feasibility of the PD for elderly patients [13-17].
The purpose of this study was to evaluate the safety of PD in patients of $\geq 75$ years of age and to show the influence of advanced age on the mortality and morbidity associated with PD.

\section{Patients and Methods}

\subsection{Patients}

Between July 2009 and December 2013, 131 patients underwent PD at Hyogo College of Medicine. These patients were divided, according to their age into an elderly group $(\geq 75$ years of age; $n=28)$ and a younger group $(<75$ years of age; $\mathrm{n}=103)$. The following preoperative data were collected: gender, age, body mass index (BMI), biochemistry tests, and preoperative complications. The following operative data were collected: operative procedure, operative time, intraoperative blood loss and postoperative complications. Pancreatic fistula was defined according to the International 
Study Group on Pancreatic Fistula (ISGPF) criteria [18]. Delayed gastric emptying and postpancreatectomy hemorrhage were also defined according to the definitions proposed by the International Study Group of Pancreatic Surgery (ISGPS) [19-20]. Perioperative mortality was defined as death in the hospital or death within 30 days of surgery.

\subsection{Surgical Procedure}

Standard PD, pylorus-preserving PD (PPPD), and subtotal stomach-preserving PD (SSPPD) were performed at the discretion of the individual surgeons. Anastomosis between the pancreas and jejunum was performed using end-to-side two-layer anastomosis with external stent drainage for the pancreatic duct. Anastomosis of the outer layer was performed between the pancreatic parenchyma and jejunal seromuscular tissue using 4-0 absorbable interrupted sutures. Anastomosis between the pancreatic duct and jejunal mucosa was performed using 5-0 or 6-0 absorbable interrupted sutures. Then, end-to-side hepaticojejunostomy was performed $15 \mathrm{~cm}$ distal from the site of pancreaticojejunostomy by one-layer anastomosis. Duodenojejunostomy in PPPD or gastrojejunostomy in PD or SSPPD was performed $50 \mathrm{~cm}$ distal from the hepaticojejunostomy site by two-layer anastomosis. All patients underwent reconstruction using modified Child's methods.

\subsection{Statistical Aanalysis}

Comparisons between groups were made using the chi-squared test, and averages were compared using Student's $t$ test. P values of $<0.05$ were considered to indicate statistical significance. Numerical data are expressed as the mean \pm SD.

\section{Results}

\subsection{Comparisons of Patient Characteristics and Preoperative Factors}

The clinicopathological characteristics of the two groups of patients are shown in Table 1.

Table 1. Patient characteristics and preoperative factors.

\begin{tabular}{|c|c|c|c|}
\hline & $\geq 75$ years $(n=28)$ & $<75$ years $(n=103)$ & $p$ value \\
\hline \multicolumn{4}{|l|}{ Background } \\
\hline Age (years) & $77.6 \pm 2.0$ & $62.7 \pm 10.1$ & $<0.05$ \\
\hline Gender (male/female) & $19 / 9$ & $69 / 34$ & 0.931 \\
\hline BMI & $21.4 \pm 2.8$ & $22.5 \pm 3.2$ & 0.105 \\
\hline \multicolumn{4}{|l|}{ Biochemistry test } \\
\hline Total bilirubin (mg/dl) & $1.7 \pm 1.9$ & $2.3 \pm 2.7$ & 0.057 \\
\hline Albumin (g/dl) & $3.6 \pm 0.5$ & $4.0 \pm 3.2$ & 0.496 \\
\hline \multicolumn{4}{|l|}{ Preoperative complication } \\
\hline Overall & $23(82 \%)$ & $64(62 \%)$ & $<0.05$ \\
\hline Brain infarction & $2(7 \%)$ & $5(5 \%)$ & 0.633 \\
\hline Pulmonary dysfunction & $9(32 \%)$ & $24(23 \%)$ & 0.339 \\
\hline Hypertension & $15(54 \%)$ & $41(40 \%)$ & 0.192 \\
\hline Ischemic heart disease & $5(18 \%)$ & $10(10 \%)$ & 0.23 \\
\hline Diabetes mellitus & $10(36 \%)$ & $26(25 \%)$ & 0.271 \\
\hline
\end{tabular}

BMI: body mass index.

Twenty-eight $(21 \%)$ of the 131 patients were $\geq 75$ years of age. The mean age of the elderly group was $77.6 \pm 2.0$ years, whereas that of the younger group was $62.7 \pm 10.1$ years. There were no significant differences between the groups with regard to sex, BMI, total bilirubin, albumin or hemoglobin. The preoperative complication rate in the elderly group (82\%) was significantly higher than that in the younger group (62\%).

\subsection{Comparisons of Surgical Factors}

Comparisons of the surgical factors are shown in Table 2.

Table 2. Surgical factors.

\begin{tabular}{|c|c|c|c|}
\hline & $\geq 75$ years $(n=28)$ & $<75$ years $(n=103)$ & $p$ value \\
\hline \multicolumn{4}{|l|}{ Diseases } \\
\hline Pancreatic cancer & $10(36 \%)$ & $39(38 \%)$ & \multirow[t]{6}{*}{0.835} \\
\hline Bile duct cancer & $8(29 \%)$ & $29(28 \%)$ & \\
\hline Cancer of the ampulla of Vater & $4(14 \%)$ & $8(8 \%)$ & \\
\hline Intraductal papillary mucinous neoplasm & $2(7 \%)$ & $8(8 \%)$ & \\
\hline Duodenal cancer & $0(0 \%)$ & $5(5 \%)$ & \\
\hline Others & $4(14 \%)$ & $14(13 \%)$ & \\
\hline PPPD & $23(82 \%)$ & $88(85 \%)$ & \multirow[t]{4}{*}{0.667} \\
\hline SSPPD & $2(7 \%)$ & $9(9 \%)$ & \\
\hline PD & $3(11 \%)$ & $6(6 \%)$ & \\
\hline Operative factor & & & \\
\hline
\end{tabular}




\begin{tabular}{|c|c|c|c|}
\hline & $\geq 75$ years $(n=28)$ & $<75$ years $(n=103)$ & $p$ value \\
\hline Operative time, mean (min) & $634 \pm 79$ & $650 \pm 126$ & 0.552 \\
\hline Intraoperative blood loss, mean (ml) & $1210 \pm 1093$ & $1377 \pm 1254$ & 0.523 \\
\hline
\end{tabular}

PPPD: pylorus-preserving pancreaticoduodenectomy, SSPPD: subtotal stomach-preserving pancreaticoduodenectomy, PD: pancreaticoduodenectomy.

The most common disease in the elderly group was pancreatic cancer, followed by bile duct cancer, cancer of the ampulla of Vater, and duodenal cancer. On the other hand, the most common disease in the younger group was pancreatic cancer, followed by bile duct cancer, cancer of the ampulla of Vater, and duodenal cancer. PD was performed in 28 patients in the elderly group (PPPD, $\mathrm{n}=23$ [82\%]; SSPPD, $\mathrm{n}=2$ [7\%]; and standard $\mathrm{PD}, \mathrm{n}=3[11 \%])$ and 103 patients in the younger group (PPPD, $\mathrm{n}=88[85 \%], \mathrm{SSPPD}, \mathrm{n}=9[9 \%]$ and standard
$\mathrm{PD}, \mathrm{n}=6[6 \%])$. The operative time and intraoperative blood loss of the two groups did not differ to a statistically significant extent.

\subsection{Postoperative Complications and Clinical Outcomes}

Comparisons of the postoperative complications and clinical outcomes are shown in Table 3.

Table 3. Postoperative complications and the clinical outcomes.

\begin{tabular}{|c|c|c|c|}
\hline & $\geq 75$ years $(n=28)$ & $<75$ years $(n=103)$ & $p$ value \\
\hline Morbidity & $18(64 \%)$ & $50(49 \%)$ & 0.139 \\
\hline \multicolumn{4}{|l|}{ Postoperative complications } \\
\hline Pancreatic fistula & $16(57 \%)$ & $41(40 \%)$ & 0.101 \\
\hline Grade B & $14(50 \%)$ & $32(31 \%)$ & \\
\hline Grade C & $0(0 \%)$ & $1(1 \%)$ & \\
\hline Delayed gastric emptying & $1(4 \%)$ & $6(6 \%)$ & 0.638 \\
\hline Intra-abdominal abscess & $1(4 \%)$ & $9(9 \%)$ & 0.361 \\
\hline Wound infection & $4(14 \%)$ & $15(15 \%)$ & 0.971 \\
\hline Ascites & $0(0 \%)$ & $4(4 \%)$ & 0.289 \\
\hline Pneumonia & $0(0 \%)$ & $1(1 \%)$ & 0.601 \\
\hline Mortality & $0(0 \%)$ & $1(1 \%)$ & 0.601 \\
\hline
\end{tabular}

There were no significant differences between the older and younger groups in the rates of mortality $(0 \%$ vs. $1 \%)$ or morbidity $(64 \%$ vs. $49 \%)$. The most common complication was pancreatic fistula (44\%). The incidence of pancreatic fistula in the elderly and younger groups was similar ( $57 \%$ vs. $40 \%$ ). There was also no significant differences in the incidence of other complications, including delayed gastric emptying, intra-abdominal bleeding, intra-abdominal abscess, wound infection, ascites and pneumonia.

\section{Discussion}

It is important to study the surgical outcomes of PD in elderly patients because of the aging of populations in developed countries. In patients with periampullary tumors, PD has been performed for curative resection during each generation. However, PD is an aggressive surgical modality with reported complication rates of 30-60\% [8-9]. PD may cause considerable complications, including pancreatic fistula, intra-abdominal bleeding and intra-abdominal abscess, and requires high-quality techniques and management in the perioperative period. Recently, the rates of morbidity and mortality associated with PD have decreased, especially in high volume centers [21-23]. Several reports have emphasized the elevated operative risks of PD in elderly patients. Finlayson et al. found a high perioperative mortality rate of up to $15.5 \%$ for patients of $\geq 80$ years of age [24]. Makary et al. examined the outcomes of PD in 207 patients of $\geq 80$ years of age and found significant increases in mortality $(4.1 \%$ vs.
$1.7 \% ; p<0.05)$ and morbidity $(52.8 \%$ vs. $41.6 \% ; p<0.05)$ among older patients [25]. Brozzetti et al. reported that the surgical complications after PD that led to reoperation were responsible for a high rate of mortality in patients of $>70$ years of age [10]. Recent studies of high volume centers for PD reported that with the application of improved surgical techniques, instruments, and perioperative management, PD could be performed safely for elderly patients with no adverse effects after the operation [12, 14-17]. In our study, although the rate of preoperative complications was significantly higher in patients of $\geq 75$ years of age ( $82 \%$ vs. $62 \% ; p<0.05$ ), there was no significant differences in the rates of mortality ( $0 \% \mathrm{vs}$. $1 \% ; p=0.601)$ or overall morbidity ( $64 \%$ vs. $49 \% ; p=0.139$ ). Although not statistically significant, surgical stressors, such as operative time ( $634 \pm 79 \mathrm{~min}$ vs. $650 \pm 126 \mathrm{~min} ; p=0.552)$ and intraoperative blood loss $(1210 \pm 1093 \mathrm{ml}$ vs. $1377 \pm 1254 \mathrm{ml}$; $p=0.523$ ) were lower in patients of $\geq 75$ years of age who underwent surgery at the discretion of the individual surgeons.

Pancreatic fistula is the most threatening complication of PD. In the literature, the reported rate of pancreatic fistula ranges from 5\% to $40 \%$ [26-29]. In our study, the incidence of pancreatic fistula in the elderly and younger groups was similar $(57 \%$ vs. $40 \% ; p=0.101)$. Several reports have compared external drainage and no-stent procedures and found that the incidence of pancreatic fistula was significantly lower when external drainage was performed [27, 30]. As anastomosis is made with the narrow main pancreatic duct was made, postoperative swelling may develop temporarily, which can result in stenosis [16]. Thus, stent placement is 
considered essential at our institution. Regarding DGE, our study showed no differences between the elderly and younger groups. However the incidence of DGE in elderly patients has been reported to be higher than that in younger patients [31]. In our study, anastomosis between the jejunum and the duodenum or stomach with antecolic reconstruction was made as straight as possible, in order to improve the physical flow until peristalsis improved. Thus, the incidence of DGE in our study was decreased in all generations in comparison to the incidence in previous reports [31].

\section{Conclusion}

The preoperative complication rate in the elderly group was significantly higher than that in the younger group. However, our study demonstrated that the surgical outcomes of PD can be similar in elderly and younger patients. We suggest that PD can be performed safely in elderly patients and that advanced age alone should not be a contraindication to PD.

\section{References}

[1] Allen O. Whipple pancreaticoduodenectomy for islet carcinoma: a five-year follow-up. Ann Surg 1945; 121: 847-852.

[2] Monge JJ, Judd ES, Gage RP. Radical pancreatoduodenectomy: a 22-year experience with the complications, mortality rate and survival rate. Ann Surg 1964; 160: 711-722.

[3] Crile G Jr. The advantages of bypass operations over radical pancreatoduodenectomy in the treatment of pancreatic carcinoma. Surg Gynecol Obstet 1970; 130: 1049-1053.

[4] Shapiro TM. Adenocarcinoma of the pancreas: a statistical analysis of biliary bypass vs Whipple resection in good risk patients. Ann Surg 1975; 182: 715-721.

[5] Grace PA, Pitt HA, Tompkins RK, DenBesten L, Longmire WP Jr. Decreased morbidity and mortality after pancreatoduodenectomy. Am J Surg 1986; 151: 141-149.

[6] Yeo CJ. Six hundred fifty consecutive pancreaticoduodenectomies in the 1990s: pathology, complications, and outcomes. Ann Surg 1997; 226: 248-257, discussion 257-260.

[7] Neoptolemos JP, Russell RC, Bramhall S, Theis B. Low mortality following resection for pancreatic and periampullary tumours in 1026 patients: UK survey of specialist pancreatic units. UK Pancreatic Cancer Group. Br J Surg 1997; 84: 1370-1376.

[8] Conlon KC, Labow D, Leung D, Smith A, Jamagin W, Coit DG, et al. Prospective randomized clinical trial of the value of intraperitoneal drainage after pancreatic resection. Ann Surg 2001; 234: 487-93, discussion 493-494.

[9] Yeo CJ, Cameron JL, Lillemoe KD, Sohn TA, Campbell KA, Sauter PK, et al. Pancreaticoduodenectomy with or without distal gastrectomy and extended retroperitoneal lymphadenectomy for periampullary adenocarcinoma, part 2 : randomized controlled trial evaluating survival, morbidity, and mortality. Ann Surg 2002; 236: 355-366, discussion 366-368.
[10] Brozzetti S, Mazzoni G, Miccini M, Puma F, De Angelis M, Cassini D, et al. Surgical treatment of pancreatic head carcinoma in elderly patients. Arch Surg 2006; 141: 137-142.

[11] Lee MK, Dinorcia J, Reavey PL, Holden MM, Genkinger JM, Lee JA, et al. Pancreaticoduodenectomy can be performed safely in patients aged 80 years and older. J Gastrointest Surg 2010; 14: 1838-1846.

[12] Khan S, Sclabas G, Lombardo KR, Sarr MG, Nagorney D, Kendrick ML, et al. Pancreatoduodenectomy for ductal adenocarcinoma in the very elderly; is it safe and justified? J Gastrointest Surg 2010; 14: 1826-1831.

[13] Fong Y, Blumgart LH, Fortner JG, Brennan MF. Pancreatic or liver resection for malignancy is safe and effective for the elderly. Ann Surg 1995; 222: 426-434, discussion 434-437.

[14] DiCarlo V, Balzano G, Zerbi A, Villa E. Pancreatic cancer resection in elderly patients. Br J Surg 1998; 85: 607-610.

[15] Tani M, Kawai M, Hirono S, Ina S, Miyazawa M, Nishioka R, et al. A pancreaticoduodenectomy is acceptable for periampullary tumors in the elderly, even in patients over 80 years of age. J Hepatobiliary Pancreat Surg 2009; 16: 675-680.

[16] Ito Y, Kenmochi T, Irino T, Egawa T, Hayashi S, Nagashima A, et al. The impact of surgical outcome after pancreaticoduodenectomy in elderly patients. World J Surg Oncol 2011; 9: 102.

[17] Yamada S, Shimada M, Utsunomiya T, Morine Y, Imura S, Ikemoto T, et al. Surgical results of pancreatoduodenectomy in elderly patients. Surg Today 2012; 42: 857-862.

[18] Bassi C, Dervenis C, Butturini G, Fingerhut A, Yeo C, Izbicki J, et al. Postoperative pancreatic fistula: an international study group (ISGPF) definition. Surgery 2005; 138: 8-13.

[19] Wente MN, Bassi C, Dervenis C, Fingerhut A, Gouma DJ, Izbicki JR, et al. Delayed gastric emptying (DGE) after pancreatic surgery: a suggested definition by the International Study Group of Pancreatic Surgery (ISGPS). Surgery 2007; 142: 761-768.

[20] Wente MN, Veit JA, Bassi C, Dervenis C, Fingerhut A, Gouma $\mathrm{DJ}$, et al. Postpancreatectomy hemorrhage (PPH): an International Study Group of Pancreatic Surgery (ISGPS) definition. Surgery 2007; 142: 20-25.

[21] Gordon TA, Burleyson GP, Tielsch JM, Cameron JL. The effects of regionalization on cost and outcome for one general high-risk surgical procedure. Ann Surg 1995; 221: 43-49.

[22] Sosa JA, Bowman HM, Gordon TA, Bass EB, Yeo CJ, Lillemoe KD, et al. Importance of hospital volume in the overall management of pancreatic cancer. Ann Surg 1998; 228: 429-438.

[23] Lieberman MD, Kilburn H, Lindsey M, Brennan MF. Relation of perioperative deaths to hospital volume among patients undergoing pancreatic resection for malignancy. Ann Surg 1995; 222: 638-645.

[24] Finlayson E, Fan Z, Birkmeyer JD. Outcomes in octogenarians undergoing high-risk cancer operation: a national study. J Am Coll Surg 2007; 205: 729-734.

[25] Makary MA, Winter JM, Cameron JL, Campbell KA, Chang D, Cunningham SC, et al. Pancreaticoduodenectomy in the very elderly. J Gastrointest Surg 2006; 10: 347-356. 
[26] Lowy AM, Lee JE, Pisters PW, Davidson BS, Fenoglio CJ, Stanford $\mathrm{P}$, et al. Prospective, randomized trial of octreotide to prevent pancreatic fistula after pancreaticoduodenectomy for malignant disease. Ann Surg 1997; 226: 632-641.

[27] Roder JD, Stein HJ, Bottcher KA, Busch R, Heidecke CD, Siewert JR. Stented versus nonstented pancreaticojejunostomy after pancreatoduodenectomy: a prospective study. Ann Surg 1999; 229: 41-48.

[28] Cameron JL, Pitt HA, Yeo CJ, Lillemoe KD, Kaufman HS, Coleman J. One hundred and forty-five consecutive pancreaticoduodenectomies without mortality. Ann Surg 1993; 217: 430-435, discussion 435-438.
[29] Montorsi M, Zago M, Mosca F, Capussotti L, Zotti E, Ribotta $\mathrm{G}$, et al. Efficacy of octreotide in the prevention of pancreatic fistula after elective pancreatic resections: a prospective, controlled, randomized clinical trial. Surgery 1995; 117: 26-31.

[30] Poon RT, Fan ST, Lo CM, Ng KK, Yuen WK, Yeung C, et al. External drainage of pancreatic duct with a stent to reduce leakage rate of pancreaticojejunostomy after pancreaticoduodenectomy: a prospective randomized trial. Ann Surg 2007; 246: 425-433.

[31] Sohn TA, Yeo CJ, Cameron JL, Lillemoe KD, Talamini MA, Hruban RH, et al. Should pancreaticoduodenectomy be performed in octogenarians? J Gastrointest Surg 1998; 2: 207-216. 